\title{
Student Perspectives on PBL: Lessons from a Graduate Course
}

\author{
Vappu Tyyskä", Mary Grace Betsayda, Akelah Jamal, Sirena Liladrie, Ramon Meza Opazo, \\ Adriann Moss, Jaihun Sahak, Jessica Walters \\ canada \\ *Corresponding Author: Vappu Tyyskä, canada
}

\begin{abstract}
PBL was utilized in a 12-week M.A. course in a multidisciplinary program in a Canadian university. Using mixed qualitative methods (course evaluations, student journals, and a focus group), the instructor/tutor and seven students evaluated the PBL process, focusing on student perspectives regarding: (1) the tutor's role and performance; (2) group dynamics; and (3) learning outcomes. The results confirm the crucial role of the tutor in the PBL process, and the generally positive sense by students that several types of learning took place. The study brings attention to the need to manage group dynamics more carefully, although even students whose group dynamics were difficult, came out with positive feelings about the PBL process.
\end{abstract}

\section{INTRODUCTION}

While Problem-Based Learning (PBL) is not a new method of instruction, its implementation in the social sciences is relatively new. PBL uses an instructional format that makes use of problems or situations (Loyens, Magda, \& Rikers, 2008) by making them a starting point of the learning process.

PBL emphasizes that students take an active approach to learning. This method brings together small groups of students learn collaboratively in the context of meaningful problems (Loyens, Magda, \& Rikers, 2008). In addressing the problem, students spend time selecting and studying literature that is relevant to the issues generated, as well as devising a plan of action and dividing the workload to arrive at a solution. The teamwork necessary for PBL allows for the students to collectively share and critically evaluate their findings, elaborate on knowledge acquired, and have an opportunity to correct misconceptions (Hmelo-Silver, 2004; Dolmans \& Schmidt, 1983). De Simone (2008) explains that the group must engage in a process of reviewing various research materials, individually explaining their conclusions to the group, collaboratively discussing findings and understanding the consequences of these options to come to a solution.

PBL has been challenged as a method of education learning (Loyens, Magda, \& Rikers, 2008). As a result of this scrutiny, proponents of PBL have clearly described its intention. Some of the goals of PBL are to construct an extensive and flexible knowledge base, build collaboration and problemsolving skills, and motivate students to engage in their learning process (Barrows, 1984, 1985, 1986; Barrows \& Tamblyn, 1980; Norman\& Schmidt, 1992).

\section{Tutor Role AND PERformance}

Although PBL is student-driven, the tutor's role is crucial (Hmelo-Silver, 2004; Speck, 2003). The tutor takes on multiple functions as a guide, facilitator, evaluator and motivator (Hmelo-Silver, 2004). Loyens, Magda, \& Rikers (2008) note that this process requires the guidance of a tutor who initiates the discussion, provides students with relevant content information, and monitors and evaluates each individual's contribution to the group. The tutor's role typically involves the initial theoretical examination which will provide context to the problem. The planning meetings allow for students to develop an understanding of the problem or issue at hand.

What is particularly challenging to the effective implementation of PBL is that it is different from other methods of learning commonly found in schools today (Pendersen, Arslanyilmaz, \& Williams, 2007). They argue that current assessment practices continue to reflect the values associated with instructor led learning and classroom management that contributed to educational thought in the early 
part of the 20th century, which are at odds with the implementation of PBL. The resulting disconnects between instruction and assessment threatens the effectiveness of alternative approaches to learning, such as PBL. Hung, Harpo-Bailey, \& Jonasson (2003) conclude that the traditional professor role and the PBL tutor role may create tensions in the PBL process. According to Nespor (1987) "Teachers' beliefs have long been shown to be powerful predictors of their practices" (as cited in Hung, HarpoBailey, \& Jonasson, 2003: p. 14). This suggests that teachers' beliefs about assessment and classroom management, and their perceptions of how student are motivated, and how others will react may impact teachers' decisions about how to implement new methods of learning.

Teachers' decisions regarding assessment practices can be influenced by the need to maximize student productivity. Some teachers' aversion to alternative teaching methods, like PBL, is defended by educators who believe in the importance of instructor- directed learning. Some teachers argue that students would either engage in unproductive tasks or become frustrated and disengage from the program entirely (Pendersen, Arslanyilmaz, \& Williams, 2007). For example, the process of grading students can be perceived as an effective method of developing extrinsic motivation in students.

Teachers tend to conduct ongoing individualized, ungraded assessment in order to help students improve (Pendersen, Arslanyilmaz, \& Williams, 2007). Given that teachers' concerns are embedded in current assessment practices, implementing PBL in classrooms by these teachers may be challenging.

The reasons why implementation can be challenging for some teachers is articulated by Budé, Imbos, Wiel, Broers, and Berger (2009) who state that instead of dispensing knowledge teachers should try to engage students by stimulating group processes, trying to create an atmosphere in which students can optimally participate in the discussions, helping students to monitor their own learning, and stimulating self-study (Schmidt \& Moust, 2000; De Grave et al., 1999). Tutors traditionally ask questions like: Can you explain this? Do you understand that? Can you see why that is important? "However, if a tutor contributes too much to the discussion in PBL, self-study time decreases" (Schmidt \& Moust, 2000 as cited in Budé et al., 2009: p. 2). The expectations of engaging students in this process are to increase students' understanding of the topics resulting in better insight into the content of the course (Budé et al., 2009). Remedios, Clarke, and Hawthorne (2008) further this reasoning, and articulate that teachers may come to perceive their jobs as facilitating students speaking rather than facilitating their learning. Another concern for some students is the PBL assessment criteria, which are based on behaviours viewed to be associated with learning rather than the outcomes of student learning alone. Because of the centrality of learning outcomes, this study will explore student perceptions of their learning process and outcomes as a result of the implementation of PBL.

\subsection{Group Dynamics}

Students, who are more accustomed to traditional instruction methods, need to develop their selfdirection and group work skills (Fiddler \& Knoll, 1995; Hung, Harpole Bailey, \& Jonasson, 2003). One of the central goals of PBL is to work together as a group to establish common grounds, resolving discrepancies and negotiating the actions that a group is going to take. In this, the role of the teacher is that of a facilitator to assist in student collaboration (Speck, 2003; Hmelo-Silver, 2004). Tutors must be able to facilitate and negotiate productive collaborative relationships in the group work atmosphere (Wilkerson, 1995; Schmidt \& Moust, 1995 as cited in Hung, Harpole Bailey \& Jonasson, 2003). After group formation, expectations relating to leadership roles within the group are an integral area for the professor to address. Speck (2003) highlights leadership as a contentious role in group dynamics which he points out must be constantly monitored by the instructor throughout the process. Conflict resolution is another key area where the instructor must establish rules for dealing with such issues. Equitable distribution of leadership roles is considered a great way to avoid conflict within the group. Dolmans et al. (2001) point out that there is a danger that these issues are addressed by reverting to the teacher-directed model which would negate the PBL process. Instead, they stress that teachers and professors should confront these issues by holding on to the educational philosophy which PBL is based: the student-directed model.

A study by Brzovic \& Matz (2009), which was based on peer evaluations in a six student focus group, revealed that when students' opened up they demonstrated higher levels of audience and selfawareness necessary to becoming better communicators. They found that when individuals opened up 
about their thoughts, the trust necessary to successful group formation increased, as did the appreciation for the ideas of others. It appeared that those individuals who had a greater understanding of group dynamics felt comfortable enough as leaders to relinquish control. Alternatively, in groups that struggled, the struggle tended to be based on an attempt to meet the personality needs of various students. Group members were stressed by having to deal with other group members' issues. In some cases PBL can be extremely demanding as it calls for both working on a task and promoting healthy relationships between members (Brzovic \& Matz, 2009).

Reflected in the research specific to group dynamics is that sociocultural factors relating to both individual and group pressures have a role in constraining verbal participation in some students. Remedios, Clarke, \& Hawthorne (2008) showed in their research that issues of learning preferences, motivation, and preparation for the session, cultural literacy, language, and concerns with group dynamics can influence participation. This may have an effect on how both the tutor and the group members perceive an individual's contribution, and thus have an impact on the dynamics of the group itself. A group member's silence does not necessarily mean s/he is passive and not learning. The notion that the degree of verbalization is directly related to the degree of learning has been challenged (Moust et al., 1987) and it has been acknowledged that being 'silent' in the group planning does not indicate that students are 'mentally passive' or have no positive learning outcomes (Chalmers \& Volet, 1997 as cited in Remedios et al, 2008: p. 212).

\subsection{Learning and Outcomes}

Research demonstrates that student-centeredness, small-group work, self-directed learning, experiential learning, and the tutor's role as a facilitator are core characteristics of PBL (Hakkarainen, 2009). In addition, PBL emphasizes the importance of critical and reflective thinking skills, contextual knowledge, and the integration of disciplines necessary to successfully adapt to the PBL method (Barrows, 1996; Hmelo-Silver, 2004; Poikela \& Poikela, 2005b). In addition, the active role of the students is considered crucial for the conversational and collaborative nature of PBL. The specific pedagogical strengths of the PBL course are in the collaborative, co-operational, and conversational characteristics of the learning process.

The PBL process that consists of collaborative learning in tutorial sessions and independent knowledge acquisition from multiple sources makes it possible to integrate the teaching and learning of various domains (Hakkarainen, 2009). The research indicated that the tutorial sessions support the students in their learning and are one of the main reasons for their active involvement in the learning process. However, to simply offer an environment is not enough. Hakkarainen's (2009) study showed that students are not necessarily convinced that they learned to acquire and evaluate information and to think critically during a course. To better support students, the teaching of information literacy skills can be integrated into the PBL course or PBL curriculum. In practice, this can mean collaboration between PBL tutors or teachers and librarians to improve their facilitation skills in the context of PBL (Breen \& Fallon, 2005; Poikela \& Poikela, 2005a, as cited in Hakkarainen, 2009: p. 2).

Loyens, Magda, and Rikers (2008) found that with respect to the learning process in PBL, students need to assess their own understanding of the problem in the context of the group. These learning issues, formulated as questions, comprise what needs to be looked up in the literature and subsequently be studied, to gain a better understanding of the problem (Loyens, Magda, \& Rikers, 2008). In PBL, students work together in groups and they formulate their learning needs collectively. Similar research by Ellis, Goodyear, Brillant, and Prosser (2008) shows that students' experiences and intentions are critical variables in the complex web of influences upon the success or failure of an educational approach like PBL. Some research, including Maudsley, Williams \& Taylor (2006), found that students were ultimately disappointed in themselves, other students and tutors during less effective sessions.

There is more need for studies that deal specifically with the time continuum of student experiences within PBL courses, from their initial reactions to the learning outcomes. This kind of study can be an effective tool for analyzing the success of the approach within and between disciplines, and can also help in the development of more refined practices within PBL frameworks. Though student experiences are addressed (Copan \& Kuhn, 2004; Hmelo-Silver, 2004), most don't capture initial reactions of students to the PBL approach and how those transform over time. Simply put, "the answer to what's good about problem-based learning is that it promotes sense making" (Copan \& 
Kuhn, 2004: p. 74). Hmelo-Silver (2004) further stresses that the process of PBL should help students develop flexible knowledge, effective problem-solving skills, and intrinsic motivation. Another benefit of group participation is that students are able to appropriate each other's expertise and recycle findings amongst each other (Hmelo- Silver, 2004: p. 246).

One of the strengths of PBL is to introduce and familiarize learners with the use of more than one resource and to deal with more than one perspective. This study will explore the learning outcomes specific to PBL use in a graduate level social sciences course to understand how, in this context, student perceptions and group dynamics, and the tutor's role influence the learning outcomes of the students.

\section{Methodology}

The 12-week graduate course consisted of five two-week PBL units in the fall of 2008. The first two weeks were spent describing and rehearsing the PBL process. During the first week of each two-week PBL unit, the 17 graduate students would get a short trigger session in the form of a lecture (30-60 minutes), followed by up to two and a half hours of in-class work in permanent tutor-assigned groups (3-4 members in each group). Group members discussed the week's thematically grouped readings, came up with a short written summary of the main findings, identified research gaps and questions, developed a tentative problem/thesis statement, and divided the work among team members. In the end of the planning session, the students handed in this one-page write- up of the required elements, for feedback and evaluation. The groups rotated the tasks of chair and note taker. The instructor/tutor spent the group work time answering student questions and concerns, and helping the groups identify their research focus and formulate a problem/thesis statement. She collected the one-page summaries in the end of the session and graded them by the afternoon of the next day, giving a detailed written feedback (1-2 pages) to the groups, covering each component of their plan (literature review, working thesis statement, division of labour).

Once the students had the feedback, they spent the time before the following class researching their problem/thesis statement, with the goal of doing a half-hour group presentation in the next class. Through the week, they communicated with one another (and the tutor if needed) about their progress, and coordinated the different components of their work.

Each group member was required to present their findings in the second week of each PBL unit. The half-hour presentations were accompanied with a one-page group- generated handout to all present, identifying the thesis statement, main findings, theories, and policy implications. In addition, each student handed in a short (max. 5 pages) essay on her/his portion of the assignment, explaining how it linked to the overall project, and outlining his/her findings, theories, and policy implications. Thus, the PBL process had both group evaluation components, as the work plans, oral presentations, and one-page presentation summaries were graded based on group performance, and the essays were graded individually.

\subsection{PBL within PBL - The Evaluation Project}

Toward the middle of the term, a student (see acknowledgement) proposed that the class engage in an evaluation of the PBL process. In the end, a team consisting of the tutor and seven of the 17 students decided to do this, after the course was over and the grades were officially submitted. It is important to note that the issue of bias is to be acknowledged because the members of the research team were also members of the graduate course at Ryerson University where this pedagogical experiment took place.

The general process of the PBL evaluation process mirrors the PBL practice of the course. The team uses Participatory Action Research, most commonly known as 'action research', to emphasize the methodological approach that allows its researchers to 'learn by doing' (O'Brien, 1998; Peters \& Gray, 2007; Hyland, 2009). Gilmore et al., 1986 (as cited in O’Brien, 1998: p. 1) define Participatory Action Research in the following way:

Action research...aims to contribute both to the practical concerns of people in an immediate problematic situation and to further the goals of social science simultaneously. Thus, there is a dual commitment in action research to study a system and concurrently to collaborate with members of the system in changing it in what is together regarded as a 
desirable direction. Accomplishing this twin goal requires the active collaboration of researcher and client, and thus it stresses the importance of co-learning as a primary aspect of the research process.

Since the researcher becomes an active part of the research, s/he does not systemically 'plan' the research, rather the approach arises during discussions/engagements with the participants (Arieli et al., 2009). Further, McTaggart (1989) speaks of participants as 'tenants' of Participatory Action Research. She argues, among other things that it is contingent on authentic participation, is collaborative, and is a systematic learning process. By 'contingent on authentic participation', the author refers to "the continuing spiral of planning, acting (implementing plans), observing (systematically), reflecting and then re-planning" (1989: p. 1). The process of Participatory Action Research also involves collaboration with the research itself, and hence, researchers are directly involved rather than observing from and 'objective' viewpoint. Lastly, it is also a systematic learning process that allows one to 'understand the relationship between circumstance, action and consequences' (Ibid, 1989: p. 1).

The instructor/PBL tutor of a Master of Arts, Immigration and Settlement Studies program at Ryerson University introduced problem-based learning (PBL) pedagogy in a multidisciplinary (social sciences and humanities) graduate course in the fall of 2007.

This was the tutor's and the students' first exposure to the small-group PBL model presented by Woods (1994), and informed by other sources emphasizing the flexibility of problem-based learning practice (Barrett et al., 2005; Mills, 2007; Stanford University, 2001).

In keeping with the Participatory Action Research method, the research team (consisting of volunteers from this cohort of graduate students) assessed the mixed qualitative methods of evaluation that were used and are described below.

\subsection{Methods of Evaluation}

The data for this PBL evaluation come from three sources: (1) official Faculty Course Surveys, (2) a focus group, and (3) student journals.

Official Faculty Course Surveys (FCS) were completed by 10 of the 17 students enrolled in the course. The FCS is an online tool to provide faculty with student feedback on courses. It involves a series of questions, some standard, others more specific, on their professor and the course, based on a sliding scale from 1 (Agree) to 5 (Disagree). An example of the questions asked in the FCS included "The instructor is knowledgeable about the course material", "The instructor stimulated my interest in the subject", and "Students are treated with fairness and respect". Generally speaking, the closer to the score is to 1 , the better the evaluation. The questions were a part of the standard student evaluation process at the university, aimed at improving the students' educational experiences and to assess the quality of teaching. The survey was included in the evaluation of the PBL process because it provided data regarding the student experience, both as a Ryerson student as well as a PBL participant. In addition, the survey uses the information of PBL participants who were not necessarily members of the research team, inserting an element of objectivity to the PBL assessment. As mentioned, because the PBL research team consisted of PBL participants, questions of bias may arise among traditional researchers, not familiar with Participatory Action Research. However, the clearly acknowledged subjectivity of the research method is tempered with not only the objectivity involved in the use of the FCS, but also through the research team's commitment to proposing improvements in future PBL pedagogical processes. Their work on this article is a testament to this primary motivation.

As a second component of the evaluation, the PBL research team ran a focus group as a way to expand on the FCS results. The focus group was an important aspect of the qualitative research process because it allowed students to elaborate and reflect on their experiences in the course. It also provided vital feedback to the instructor. The student focus group developed questions additional to those in the FCS, to capture issues related to the PBL format, learning styles, and depth of learning. While the FCS allowed for comments, the research team decided to specifically discuss the tutor's role and performance as a way to capture more detail. The students were asked prior to the focus group to brainstorm and submit further questions. The focus group lasted for approximately one hour, with six of the seven students from the PBL evaluation team participating. One student (with previous research experience with focus groups) facilitated, recorded, and transcribed the focus group session. The tutor was not in attendance, so that students would be able to speak freely and openly. 
To ensure anonymity, the group ensured that all students' names were omitted from the final manuscript before it was submitted to the tutor and that both the CD and the MP3 recordings were destroyed once the research was finalized. Building on previous experience, the focus group facilitator ensured that all participants had an opportunity to speak and that no one person dominated the conversation.

The third data source was voluntary and anonymous journals handed in by four students, addressing both course content and format, including tutor role, group dynamics, and learning outcomes. Only the tutor had access to and analyzed the data related to group dynamics, to ensure that each student team participant remained anonymous to one another. All information that could have identified the students was removed from the transcripts sent by the tutor to the students for the purposes of integrating the data with other evaluation components.

\section{RESULTS AND DISCUSSION}

\subsection{Tutor Role and Performance}

This segment will summarize the students' evaluation of the tutor's role and performance generally. A big part of the tutor's role is dealing with emerging group dynamics which will be discussed separately in the next segment.

The tutor's role and performance were assessed independently by two pairs of students from the PBL evaluation team: one pair relied on the student journals as a source, and the other pair focused on the Faculty Course Surveys (FCS) and the focus group results. Due to the qualitative methodology that was employed, the results were gauged by the amount of positive wording versus criticism that was involved from both sources. In the case of the FCS, the evaluations also employed coding standards in addition to numerically ranked responses to questions.

According the numerically ranked responses in the FCS, the results were excellent: the average ratings for questions answered never surpassed 1.6. For example, "The course material is presented with enthusiasm" averaged at a 1.0. The lowest average was 1.6, responding to the statement, "Student presentations contribute significantly to this course", which is still a very good score (anything under 2.0 is considered very good). Additional written student comments on the FCS, and on student journals were overwhelmingly positive about the tutor, regarding her availability, responsiveness, and creating a comfort level among students. The student journals describe her as "a great instructor", "fantastic", "accommodating and enthusiastic", and "open to our criticism regarding the process and open to suggestions about things that needed to be changed." And although one student was critical of the PBL process, s/he said that the instructor's "enthusiasm kept me interested."

The focus group participants agreed that a PBL tutor needs to have strong organizational and communication skills, be dedicated to the PBL process, and be friendly and approachable. They saw this specific instructor as a "guide and a mentor". One student said:

I never felt scared about saying "I don't know this, I don't think I can do this" who says that to a professor? I've said that to her and she was like, "don't worry" and she helps you. So there has to be some element of this caring relationship between the professor and the student as well and that's where I think fairness and respect comes into it because that's where she was able to adjust to different individuals' unique problems that they were experiencing.

Another student added:

I think the person has to be a strong person emotionally because, even as she told us, the process was very hard for her, especially when we were being all critical. It was very difficult for her and she didn't change it. She stuck by it, and didn't change it; she didn't even modify it that much. All she said was that the trigger sessions might change a bit but she stuck with it $100 \%$. She was confident in it, she believed in the process and even though it affected her as well, for someone that isn't able to see the constructiveness in that feedback from the students or not allow it, it wouldn't work. So I think the person definitely has to be strong willed and grounded. 
Hung, Harpole Bailey, \& Jonasson (2003) note that professors who consider themselves content experts have a more difficult time taking on this new role. This was addressed by the tutor, reminding the students that her role was to be a "guide on the side" as opposed to "a sage on the stage".

The instructor also stressed the idea of moving away from "the talking head" model. In the student journals, this concept was addressed by one student who wrote:

It was interesting how the PBL wanted to eliminate 'the talking head' model that forms most of the courses we take, either in elementary school, secondary school and even in our undergraduate. I have read the recent McLean's [magazine] article that infamously dissects universities every year. One [article] spoke of a prof [...] who 'lectures' to over 3,500 students in a first year psychology course online. He is literally is 'The Talking Head'... One of my classmates said that PBL is not just one talking head, but, [instead] several. This was clearly not the intention of the PBL model, but it raises a good point.

Evidently, the general point about "the talking head" was interpreted differently by students, not necessarily as a reduction in the traditional instructor role as the main talker, but as anyone talking. This raises the question of utilizing different presentation methods. This was raised in one of the built-in in-class feedback sessions, and the class developed two gradual changes to the presentation format, i.e.: (1) utilizing film to cut down on the amount of talking, and (2) the use of posters in the final presentation session.

\subsection{Group Dynamics}

Concerns related to the group dynamics of the PBL were collected from the journals submitted by four students. Although conventional research methodology dictates that the subject of the research and the research team involving the same people is problematic due to bias, it is important to recognize, in accordance with the Participatory Action Research approach, that both positive and negative feelings were recorded. In a completely biased forum, it is assumed that the comments in the journals would be more on the positive side of the spectrum by virtue of 'promoting' PBL pedagogy. However, journal writing is an important pedagogic technique that encourages students to open up regardless of what the teacher (who is normally also the audience) thinks. Student journals were identified by the research team as a valuable asset to their work because of the rich data provided on a qualitative level. The anonymity of the comments also added another layer of truth to the data as the focus group session was a forum where self-anxiety would be higher because of the possibility that comments could be traced to a particular participant.

Relatively typical concerns arose from the journals, related to entries written prior to the beginning of the actual PBL process. At the outset, in addition to general anxiety regarding the PBL process, or group dynamics in particular, students identified other issues, including becoming "academically dependent" on other students rather than working independently; student competition; and "conflict regarding academic priorities, approaches, and working habits." Some listed concerns with some group members appearing "too bossy", and being stuck with the group whether you like it or not.

In analyzing what actually went on, as compared to the students' anticipatory fears outlined above, the students' general comments about their actual group dynamics were divided. For most, it was good:

I felt that we had PBL success and were a strong group with a good working dynamic...Everyone was pretty much a part of the process one way or another, which contributed to our group moving in the forward direction that we did...On the whole, team dynamics worked and we cooperated well together.

In one group, it was a struggle as one participant wrote in their journal: "The group dynamics were probably the most frustrating part of the PBL process. My group was probably the most dysfunctional out of the four groups." Their problems were evident to other students as well: "Other groups had some good chemistry, but I noticed one group did not have the same enthusiasm or energy." 
In the student journals, specific areas were identified as sources of conflict within groups about: communication, following rules, sharing the workload, and emotions and caring within groups, all of which will be discussed below.

\subsection{Communication}

In their journals, students stressed that: "Effective communication is probably one of the most essential tools we needed to grasp and use to handle the group dynamic issues. While one student reported that communications within the group were generally "respectful", "understanding", and "compassionate about group members' needs", all of the journals revealed some negative elements. One example was simply getting to the task and coordinating everyone's efforts:

I found it frustrating... because although we did the readings, it is hard for four minds to; one, connect with the material and two, decide on a theme or research question from which we can find four areas of research to support it. This can be a point of distraction for me.

Another comment from the journals reflects the impatience of some students with the group discussion process:

Frustration was always apparent during the planning and literature review stage as we had difficulty in generating discussion about the relevant articles. One or two members of the group were more concerned with getting the process over with, not discussing the relevant articles.

This may also be linked to difficulties of respectful communication in groups. Two of the journals commented that people were not listening to one another, but just tried to get their own views heard.

\section{FOLLOWing Rules}

One of the rules was that students had to negotiate their group's thesis, communicate to the tutor for an agreement, and divide required research tasks accordingly. However, three of the four student journals spoke of frustrations with group members not following these rules. For example, individual students would present their individual thesis to the tutor, without the group's consent. This seemed to threaten group dynamics. One student commented on competition over specific topics within the group but said that these were ironed out by either discussion or selectively ignoring statements by group members that could have led to open conflict.

Sharing the workload

Typical to any group work, there was agreement that there were some group members were "free loaders" who were not doing their share. One student called this the "most frustrating part" about the process:

The group work was often a challenge, regardless of the ground rules set. Team members often did not do their readings in preparation for the PBL leaving those who did do the readings with more work to do in the planning sessions.

There also were issues initially, with loss of group members who left the course. Though one student said that "we just did what we had to do...some picked up the slack," she also said that division of work continued to be problematic, to the point that she had to "put her foot down" in the very end to protect herself from doing an unfair share.

Specific comments related to the issue of having to take turns being chair and note taker for the group. Despite agreement, the same people monopolized the chairing role; by reportedly being either "being the most vocal" or "the ones with the strongest personality", while "power acquiescence [by other team members] had to occur in order to keep peace." The group with the difficult interpersonal dynamics spoke about "lack of trust" in one another to fulfill the required roles.

\subsection{Emotions and Caring}

One important goal of the PBL process is to facilitate the process of a group turning into a team (Woods, 1994). Only one aspect of this is dealing with sharing the work and dealing with role 
assignations. A less discussed aspect of team building is dealing with emotional/psychological issues of group members, or their personally stressful circumstances which may require attention by their group members. Two journals revealed examples of non-course-related issues of group members that, nevertheless, needed to be managed in order to accomplish PBL tasks. In the case of the one discordant group, the emotional tone of the interactions proved to be destructive:

From day one we didn't hit it off, and this feeling remained throughout the process...Team dynamics were usually stressful and became more negative between certain members of the group. There was hostility which made the planning process even more stressful...I always felt somewhat frustrated that we had to remain with the same group members throughout the whole process.

In the end, some students reported progress in their journals in learning to appreciate one another's work styles and became more flexible:

So even when planning occurs and each member knows their role there can be breakdowns in communication based solely on work styles and how tasks are completed. The final assignment style was varied to add an element that is similar to a "fair setup" where students were encouraged to incorporate a poster board or visual element in addition to their presentations allowed us to see in a way the other presentations had not that we have to be flexible and adaptable to others.

\subsection{The Issue of Progress: PBL Feedback Sessions}

Throughout the PBL process, there were built-in feedback sessions which allowed for students to voice their issues and concerns. The course content issues and some other student concerns were dealt with (see e.g. the issue of student disengagement with the presentation format, and trigger sessions, discussed in this paper). However, the students in the PBL evaluation team issues revealed that group dynamics were not addressed adequately.

Group dynamics are not as utopian as initially proposed. [I] [f]elt like I could not approach the prof about group dynamics because I felt it would have reflected poorly on me; for example, seemed like I was complaining or being "catty".

I remember leaving [the introductory class] thinking if there were problems in the group dynamics it was the fault of the person who was complaining, I think if a more realistic approach was taken...I might have felt more comfortable discussing it with the group and the instructor.

This student made some good suggestions for future improvements:

In hindsight, I think a cool way to address group dynamics was to do team building exercises and activities especially at the beginning and throughout the process that would allowed us to get to know each other better, our working and learning styles, some personality traits etc.

Another student gave feedback about how the division of work could be handled in groups:

The note taking was more challenging than the chairing because so many ideas were being thrown around and discussed and perhaps it may be more successful if there was a flip chart or board available where ideas can be put in a parking lot to grant the note taker some reprieve.

Yet another one proposed that mixing up the groups would have been a good idea:

Group dynamics could have been helped if we shifted groups instead of remaining with the same one for the semester. In a way, the same issues always played out because our personalities were a constant. Although I had a good time with my group and bonded with them, 
there were other students that I would have liked to work with, so that we could have mixed up the group dynamics a little. Perhaps there could have been a more eclectic mix of presentations and topics if our groups were shifted.

Yet another recommendation by the students was that the philosophy of student- directed learning needs to be revisited throughout the process and clarified for students. This alone would serve to reinforce constructive group behaviours.

Despite the overall positive commentary from the Faculty Course Survey (FCS) about the tutor being "amazing", it is apparent that the tutor's lack of experience with PBL resulted in a gradual deterioration of group dynamics. The insights from the students in alleviating this could have been incorporated through the PBL process, through more attention to discussions and team building exercises.

Fortunately, and possibly because of the maturity of this group of MA students compared to the younger undergraduate students, group dynamics didn't become a serious problem overall. The students' journals told of instances of learning to compromise, and of mutual help in finding resources for one another and helping one another through the presentations. Surprisingly, even the discordant group's members reported progress in team building and their increased appreciation of their team members:

My view of certain people in the group changed throughout the process. Whereas initially I thought the person was lazy and didn't care, it became clear later on that there was a certain good nature and humour which I began to appreciate as the hostility in the group grew. There was always some congratulations said to one another after our presentations but this was usually kept brief.

Other general comments in the student journals include appreciation of the role of peers, the interactivity of the learning context, and of the friends they made:

It's been over a week since the PBL class is over. We received our final grade and I could not help but e-mail my group members on our job well done. I even met up with one on Monday to have some dinner and we both agreed that we are going through "PBL withdrawal" which encompasses feelings of loss and being lost.

It is important to acknowledge the methodological challenge of interpreting comments derived from the Faculty Course Surveys. It would be interesting to look at the dynamics of how students comment of Faculty Course Surveys and how much they truly reflect the feelings of the students. What could be taken into account are: the social and academic climate in which they are administered, and what factors influence positive, negative and/or constructive criticism. What must also be taken into account are the students' attitudes towards school administration and whether they feel like their voices would really be taken into account or "heard".

\subsection{Learning Outcomes PBL Format and Process}

Initially, the students were all in general agreement that the PBL format required more work than a "regular course". Even beyond the actual work itself, the commitment required was more intense than in other courses simply because the students were accountable to their entire group and not just themselves. As a result, there was a general sense that the PBL process was a burdensome one, while its potential rewards remained unclear and/or unconvincing. A comment from the focus group illustrates this point:

I wouldn't say nothing went wrong because there were obviously times of frustration but at the same time you learn how to manage that and just the fact that you are accountable to yourself, to other people not even just in your work group but also to the class in itself. That really speaks volumes about how engaged we became if we weren't disenchanted at first and we were able to manage ourselves and other people. That was important. 
Initially, the experience was frustrating because the deadlines for the creation of the 'plan' were firmly set. During the first few sessions, students generally felt as if there was a lot more pressure on them than there needed to be as a result of having to complete a work-plan during class. Another focus group comment addresses this issue:

I found frustrating at the beginning [and] even afterwards, even at the end, was the fact that like we have to work on this every single weekend. And because we were working on it every single weekend, a lot of other school stuff got pushed aside.

Students also commented on progress with the trigger sessions. Initially, students felt that the trigger sessions were conducted too quickly but they also understood that they needed adequate time to get started on their group work. Some felt that the trigger sessions were a 'waste of time' during the first sessions. During the focus group, this was highlighted with this comment:

I thought the weakest part of the course were the trigger sessions. I really don't think I got anything out of any of them to be honest with you. Especially the first ones, even afterwards, [the tutor] did get better at them but I still feel that we really didn't draw our direction from the trigger sessions. And while we were there, I felt like getting it over with so we could start doing the thing right...That's what I felt about it. I don't think they were very productive for me.

Significantly, this changed once the students and the tutor reflected on the trigger sessions and together brainstormed ways of improving them.

I thought it was good for addressing theory relevant and the main themes that came out of all the articles. Just a good refresher. Like when most people read them the night before or several nights before so I think it's important to have that at the beginning. But I think they did get progressively better especially when she was adding the parts at the end where she was looking at research questions, like possible things to think about if you were having trouble initiating that with your group. I thought that was beneficial.

Similar progress took place with the presentations. Initially, presentations by other groups were regarded as "down time", as students did not feel that they were engaged in any other presentations other than their own. This is arguably the result of being so ingrained in the traditional instructor-led model of learning that anything peers say is seen to be of less importance (Woods, 1994). The time pressures the students felt may also have resulted in them being preoccupied with their own performance:

Initially, doing presentations and being under time constraints, how to best present material in a cohesive way and so it doesn't look disjointed like people are reading off their essays. I think that was one of the things that challenged me the most and maybe challenged our group the most.

Additionally, people who felt a bit shy thought that the process was not going to work out for them because of the mandatory presentations and also because of the emphasis placed on discussion within groups. Through the PBL process, as least one student overcame her shyness, evident in her focus group comment: "Because we had been working with each other for months, I felt like I could constructively be critical without feeling shy!"

As time went on, many students began to engage more with the presentations and saw the usefulness of incorporating the work of other groups into that of their own. This adjustment was a result of the presentations becoming more polished in interesting and also of a gradual willingness to engage in PBL process more fully - which meant engaging with other groups as well.

Most students understood that in order to have a functioning group, proper team building techniques would have to be adopted. This became crucial to the process of learning. Some of the ways this was achieved included getting together with group members and the tutor outside class and outside school premises, and increasing engagement with each others' presentations. 
It was apparent in the evaluation of the process that being willing to learn from one another required major adjustments. Team members who generally did not agree on all the issues had to compromise for the sake of the group. Open communication and honesty have to be developed and are essential for PBL to work properly. An open and honest environment within the group creates a comfort level which alleviates some of the perceived obstacles of working in a group.

\subsection{Learning Content}

To repeat, "the answer to what's good about problem-based learning is that it promotes sense making" (Copan \& Kuhn, 2004: p. 74). Learning outcomes emphasized the notions of conceptual integration and the development of a deeper understanding of the given topic. One student wrote in their journal: "I found that my learning regarding specific topics increased due to the group work and the necessity to obtain additional resources outside of the course materials."

In data from student journals, self improvement was highlighted. One student wrote that "the PBL model forced me to practice [public speaking] bi-weekly and I was able to learn and incorporate different aspects of what worked and what didn't in presentations."

Addressing the "student-as-teacher" dynamic, one student's journal emphasized that the PBL process prepared them for Masters and $\mathrm{PhD}$ streams since their skills at topic choice, independent research and expertise, as well as presentation were consistently being honed. The student wrote:

As a graduate student, we are certainly seasoned in the art of being taught. However, how much teaching do we do? As a Teaching Assistant, you are still accountable for knowledge that is gathered under your professor's bias and expertise. However, being lead in a direction with clues from a trigger session, then exploring what is out there is certainly a challenge.

Hmelo-Silver (2004) further stresses that the process of PBL should help students develop flexible knowledge, effective problem-solving skills, self-directed learning, effective collaboration skills, and intrinsic motivation. The benefit of attaining flexible knowledge means that students will be able to add new knowledge onto old ones - returning to the idea of integration.

The active engagement of identifying what students know and need to know, set strategies as to how to fill in the missing gaps and implement them, allows for development of real-life working skills that extend beyond the class room. This includes improvements in being able to work in a team. This requires listening, inputting, building consensus and working collaboratively to resolve issues. Another benefit of group participation is that students are able to appropriate each other's expertise and recycle findings amongst each other (Hmelo-Silver, 2004: p. 246). One student said: "[Be]cause we choose our own focus for discussion -- we are 'forced' to do the readings and engage in the material -- the accountability that comes from working in a group setting."

In sum, according Hmelo-Silver (2004: p. 256), being self-directed results in acquiring "the skills needed for lifelong learning." One student wrote in a journal: "The learning depth was much richer and engaged compared to non-PBL classes, because the process involved constant and diverse attention." And all criticism of the regimentation of working life aside, the positive feelings about learning beyond the immediate are reflected in one student's focus group comment:

Do you know what else? It is unbelievable how disciplined you become after finishing this process. Nobody has ever handed in an assignment late. We had deadlines, even coming up with a thesis; we had that three hour mark. Everything was scheduled and timed. Nothing ever went wrong in that class and I think its one of the key skills that we acquired through the PBL is discipline, like hard core discipline and you had no choice.

\section{CONCLUSION}

In the end, the PBL evaluation team identified both strengths and weaknesses in the implementation of the PBL method in this multidisciplinary graduate studies context. The evaluation confirms Pendersen, Arslanyilmaz, and Williams (2007) research which argues the crucial role of the tutor in the PBL process. Even if the pedagogy is meant to be student-driven, the tutor needs to be alert and 
open to the process, making it very demanding especially to someone without previous PBL experience.

This evaluation project alerts PBL practitioners to pay particular attention to group dynamics and helping students deal with the many issues that may arise when working with one another, ranging from work styles to personality traits. It is of particular note that in order for groups to turn into wellfunctioning teams, personality issues (including emotional needs of students), need attention. Surprisingly, despite the tutor's apparent shortcomings in helping students with the team building process, the students reported positive feelings and appreciation towards both their groups and individual team members. This requires further research and also raises the question whether formal (and typically instructor-driven) team building exercises would necessarily be helpful, or whether they might undermine the student-driven philosophy of PBL. In this instance, the students effectively mediated their group dynamics and developed positive and, in some instances, close relationships with one another. Though members of one group were quite unhappy with their group dynamics, they managed their work effectively and came out with a positive outlook on the process in the end.

As previously mentioned there is a need for more research that allows the students to evaluate the PBL process from the beginning to the end in regards to process and learning outcomes. Our evaluation shows that there is definitely progress happening in most areas. Students seem to move from some degree of resistance toward embracing and appreciating the PBL method. The open criticism and many suggestions for improvements by the students will go toward enhancing the PBL experiences of the next cohort of graduate students in the course.

In the end, the students described the PBL process as a stressful yet rewarding experience. In a fitting metaphor, in their journal, one student concluded:

We likened the experience to "The Apprentice", the show with Donald Trump and his participants carrying out work projects around Manhattan. Every week we were challenged in some way and accountable to others, balancing intellect with group dynamics and personal politics only for our efforts to culminate in a presentation (more like "face off") with other groups who were in the same circumstances. Who says TV can't teach you anything?

\section{ACKNOWLEDGEMENT}

Our team would like to thank Kate Dadey who, as a student in the course, came up with the idea of evaluating the PBL process.

\section{REFERENCES}

[1] Arieli, D., Friedman, V.J., Stern, M., \& Agbaria, K. (2009). The paradox of participation in action research. Action Research, Vol. 7(3), 263-290.

[2] Barrett, T., McLabhrainn, I., \& Fallon, H. (Eds.) (2005). Handbook of enquiry and problem- based learning. Irish case studies and international perspectives. Galway: CELT. Retrieved from http://www.aishe.org/readings/2005-2/copyright.html

[3] Barrows, H. S. (1984). A specific, problem-based, self-directed learning method designed to teach medical problem-solving skills, self-learning skills and enhance knowledge, retention and recall. In H. G. Schmidt, \& M. L. De Volder (Eds.), Tutorials in problem- based learning. Assen: Van Gorcum.

[4] Barrows, H. S. (1985). How to design a problem-based curriculum for preclinical years. New York: Springer.

[5] Barrows, H. S. (1986). A taxonomy of problem-based learning methods. Medical Education, 20, 481-486.

[6] Barrows, H. S., \& Tamblyn, R. (1980). Problem-based learning: an approach to medical education. New York: Springer.

[7] Breen, E., \& Fallon, H. (2005). Developing student information literacy to support project and problembased learning. In T. Barrett, I. Mac Labhrainn, \& H. Fallon (Eds.), Handbook of enquiry \& problem based learning: Irish case studies and international perspectives (pp. 179-188) [Electronic version]. All Ireland Society of Higher Education and Higher Education Authority.

[8] Brzovic, K. \& Matz, S. (2009). Students advise fortune 500 company: Designing a problem based learning community. Business Communication Quarterly, 72, 21-34. Retrieved from http://bcq.sagepub.com/cgi/ content/abstract/72/1/21 
[9] Budé, L., Imbos, T., Wiel, M., Broers, N., and Berger, M. (2009). The effect of directive tutor guidance in problem-based learning of statistics on students' perceptions and achievement. The International Journal of Higher Education and Educational Planning, 57, 1-14. Retrieved from http://www.Springerlink.com/ content/0018-1560

[10] Copan, N., \& Kuhn, D. (2004). What's so good about problem-based learning? Cognition and Instruction, 22, 61-79. Retrieved from http://www.informaworld.com/smpp/content $\sim \mathrm{db}=\mathrm{all} \sim$ content $=\mathrm{a} 783762541$

[11] De Grave, W. S., Dolmans, D. H. J. M., \& Van Der Vleuten, C. P. M. (1999). Profiles of effective tutors in problem-based learning: Scaffolding student learning. Medical Education, 33, 901-906. Retrieved from http://www.fdg.unimaas.nl/educ/cees/cv/Publications/1999/Profiles\%20of\%20effective\% 20tutors\%20in\%20problem-based\%20learning.pdf

[12] De Simone, C. (2008). Problem-Based Learning: a framework for prospective teachers' pedagogical problem solving. Teacher Development,12, 179-191. Canadian Research Knowledge Network.

[13] Dolmans, D. H. J. M., \& Schmidt, H. G. (2000). What directs self-directed learning in a problem-based curriculum? (p. 251-262) In Evensen, D. H., \& Hmelo, C. E. (eds.), Problem-based learning: A research perspective on learning interactions. Mahwah, NJ: Erlbaum.

[14] Dolmans, D., Wolfhagen, I., Van der Vleuten, C. \& Wynand H F W Wijnen. (2001). Solving problems with group work in Problem-Based Learning: hold on to the philosophy. Medical Education. 35, 884-889. Retieved from http://www3.interscience. wiley.com/journal/118991629/abstract?CRETRY=1\&SRETRY =0

[15] Ellis, R., Goodyear, P., Brillant, Prosser, M. (2008). Student experiences of problem-based learning in pharmacy: conceptions of learning, approaches to learning and the integration of face-to-face and on-line activities. Advancement in Health Science Education, 13, 675-692. Retrieved from http://www.springer link.com/content/w4q2536511018166/

[16] Fiddler, M.B., \& Knoll, J.W. (1995). Problem-based learning in an adult liberal learning context: Learner adaptations and feedback. Continuing Higher Education Review, 59, 13- 24.

[17] Hakkarainen, P. (2009). Designing and implementing a PBL course on educational digital video production: lessons learned from a design-based research. Educational Technology Research and Development, 57, 211-228. Association for Educational Communications and Technology.

[18] Hmelo-Silver, C. (2004). Problem-based learning: What and how do students learn? Educational Psychology Review, 16, 235-266. Retrieved from http://www.springerlink.com/content/j360715xw08586 $6 \mathrm{r} /$

[19] Hung, W., Harpole Bailey, J., \& Jonasson, D. (2003). Exploring the tensions of problem-based learning: Insights from research. New Directions for Teaching and Learning, 95, 13 - 23.

[20] Hyland, N. (2009). Opening and closing communicative space with teachers investigating race and racism in their own practice. Action Research, 7, 335.

[21] Loyens, S., Magda, J., \& Rikers, R. (2008). Self-Directed Learning in Problem-Based Learning and its Relationships with Self-Regulated Learning. Educational Psychological Review, 20, 411-427. Retrieved from http://www.eric.ed.gov/ERICWebPortal/Home.portal;jsessionid=Hw8JK2h1DjGhyJXdyWlMqmTw m1WJqQy7brvjT17nJpG5g9hn3yzv!2041583107?_nfpb=true\&_pageLabel=ERICSearchResult\&_urlType $=$ action $\&$ newSearch=true\&ERICExtSearch_SearchType_0=au\&ERICExtSearch_SearchValue_0=\%22Lo yens+Sofie $\% 22$

[22] Maudsley, G., Williams, E., \& Taylor, D. (2008) Problem-based learning at the receiving end: A 'mixed methods' study of junior medical students' perspectives. Advanced in Health Sciences Education, 13, 435451. Retrieved from http://www.springerlink.com/content/11pk47p11860/?p=b0a942087da54ba3b0ea 926500b 212e6\&pi=7

[23] McTaggart, R. (1989). "16 Tenants of Participatory Research Action". Retrieved from http://www. caledonia.org.uk/par.htm

[24] Mills, D. (2007). Birmingham, UK: Centre for Sociology, Anthropology, Politics. Retrieved from http://www-c-sap.bham.ac.uk/resources/project_reports.

[25] Nespor, J. (1987). The role of beliefs in the practice of teaching. Journal of Curriculum Studies, 18, 197206.

[26] Norman, G. R., \& Schmidt, H. G. (1992). The psychological basis of problem-based learning: A review of the evidence. Academic Medicine, 67, 557-565.

[27] O'Brien, R. (1998). An Overview of the Methodological Approach of Action Research. Retrieved from http://www.web.net/ robrien/papers/arfinal.html.

[28] Pendersen, S., Arslanyilmaz, A., \& Williams, D. (2009). Teachers' assessment-related local adaptations of a problem-based learning module. Educational Technology Research and Development, 57, 229-249. Retrieved from http://www.springerlink.com/content/wn10917u4855/?p=009be9e6398643c9818ab016e1 9d8d39\&pi=3 
[29] Peters, J.M., \& Gray, A. (2007). Teaching and learning in a model-based action research course. Action Research, 5, 319-331. Retrieved from http://arj.sagepub.com/cgi/content/abstract/5/3/319

[30] Poikela, E., \& Poikela, S. (2005). The Strategic Points of Problem-Based Learning-Organising Curricula and Assessment. In E. Poikela \& S. Poikela (Eds.), PBL in context: Bridging work and education (pp. 722). Tampere, Finland: Tampere University Press.

[31] Remedios, L., Clarke, D., \& Hawthorne, L. (2008). The silent participant in small group collaborative learning context. Active Learning in Higher Education, 9, 201-216.

[32] Schmidt, H. G., \& Moust, J. H. C. (1995). What makes a tutor effective? A structural-equations modelling approach to learning in problem-based curricula. Academic Medicine, 70, 708- 714. Retrieved from http://www.eric.ed.gov/ERICWebPortal/custom/portlets/recordDetails/detailmini.jsp?_nfpb=true\&_\&ERI CExtSearch_SearchValue_0=ED385189\&ERICExtSearch_SearchType_0=no\&accno=ED385189

[33] Schmidt, H. G., \& Moust, J. H. C. (2000). Factors affecting small-group tutorial learning: a review of research. In D. H. Evensen \& C. E. Hmelo (Eds.), Problem-based learning: a research perspective on learning interactions. Mahwah: Lawrence Erlbaum Associates Publishers.

[34] Sharp, D. (2003). Problem-based learning in an MBA economics course: Confessions of a first time user. New Directions for Teaching, and Learning, 95, 45-51. Retrieved from http://www3.interscience.wiley. com/journal/106557109/issue

[35] Speck, B. W. (2003). Fostering collaboration among students in problem-based learning. New Directions for Teachers and Learning, 95, 59-65. Retrieved from http://www3.interscience.wiley.com/journal/10655 7114/abstract

[36] Stanford University. (2001). Problem-based learning: speaking of teaching. Stanford University Newsletter on Teaching, 11. Retrieved from http://ctl.stanford.edu/Newsletter/problem_based_learning.pdf

[37] Tyyskä, V., Mary Grace Betsayda, Akelah Jamal, Sirena Liladrie, Ramon Meza Opazo, Adriann Moss, Jaihun Sahak, Jessica Walters. (2008). Utilizing problem-based learning in a graduate course: A Ryerson experiment. Toronto: Ryerson University Annual Faculty Conference, May 13, 2008.

[38] Woods, D.R. (1994). Problem-based learning: how to gain the most of PBL. Hamilton: McMaster University/Griffin Printing Ltd.

Citation: Vappu Tyyskä, et.al., "Student Perspectives on PBL: Lessons from a Graduate Course" International Journal of Humanities Social Sciences and Education (IJHSSE), vol 7, no. 10, 2020, pp. 01-15. doi: https://doi.org/10.20431/2349-0381.0710001.

Copyright: (c) 2020 Authors. This is an open-access article distributed under the terms of the Creative Commons Attribution License, which permits unrestricted use, distribution, and reproduction in any medium, provided the original author and source are credited. 